\title{
The role of nitric oxide in priming-induced low-temperature tolerance in two genotypes of tomato
}

\author{
Rayhaneh Amooaghaie* and Khorshid Nikzad \\ Department of Biology, Faculty of Science, Shahrekord University, Shahrekord, Iran
}

(Received 30 September 2012; accepted after revision 26 January 2013; first published online 6 March 2013)

\begin{abstract}
The present study was conducted to evaluate the contribution of nitric oxide (NO) to the priming effects on seed germination, seedling vigour and lowtemperature tolerance of two tomato cultivars (Solanum lycopersicum, cv. Cherry and Falcato) under four different constant temperatures (10, 15, 20 and $25^{\circ} \mathrm{C}$ ). Treatments included priming in a polyethylene glycol 6000 (PEG 6000) solution (osmopriming) or presoaking in sodium nitroprusside (SNP) solution, a donor of $\mathrm{NO}$, for $24 \mathrm{~h}$ at $25^{\circ} \mathrm{C}$. Suboptimal temperatures reduced seed germination and subsequent seedling growth, as well as amylase activity, in both cultivars, but Falcato was more sensitive to low temperature than Cherry. Both osmopriming and SNP treatments enhanced germination capacity, germination index, seedling root and shoot length, $\alpha$ - and $\beta$-amylase activities and sugar content under suboptimal temperatures, especially in Falcato. We observed similarities between the modes of action of the two priming treatments. Both treatments increased seed NO content, whereas their positive effects on germination and subsequent seedling growth under low-temperature stress was reversed by the addition of methylene blue (MB), a scavenger of NO. This is the first report that suggests that positive effects of priming are most likely mediated through NO signalling.
\end{abstract}

Keywords: germination, low-temperature tolerance, nitric oxide (NO), osmopriming, tomato

\section{Introduction}

Nitric oxide (NO), a highly reactive, membranepermeable free radical, is a widespread intracellular

*Correspondence

Email: rayhanehamooaghaie@yahoo.com and intercellular messenger with a broad spectrum of regulatory functions in many physiological processes. In the past 20 years NO has been reported to be involved in various key physiological processes of plants, including seed germination, leaf senescence, ethylene emission, stomatal closure, and various plant responses to biotic and abiotic stresses, such as salinity, drought and ultraviolet (UV)-B-radiation (Neill et al., 2003; Delledonne, 2005). It has been reported that molecules such as NO can enhance germination and/ or break dormancy in seeds (Beligni and Lamattina, 2000; Beligni et al., 2002; Neill et al., 2003; Simontacchi et al., 2004; Zhang et al., 2005; Bethke et al., 2007) and significantly impact plant growth and development (Lamattina et al., 2003; Neill et al., 2003; del Rio et al., 2004). Gouvea et al. (1997) reported that exogenously applied sodium nitroprusside (SNP), as an NO donor, can enhance elongation growth in maize root segments, and application of methylene blue (MB), which inhibits NO production and/or NO action in plants, could reverse these responses.

Gould et al. (2003) reported that heat, osmotic and salinity stresses induced a rapid increase in $\mathrm{NO}$ production in tobacco cells. Furthermore, application of SNP alleviated the toxic effects caused by heat stress in weed calluses by decreasing hydrogen peroxide $\left(\mathrm{H}_{2} \mathrm{O}_{2}\right)$ and malondialdehyde (MDA) contents and increasing the activities of superoxide dismutase (SOD), catalase (CAT), ascorbate peroxidase (APX) and peroxidase (POD) (Song et al., 2006). The positive effect of $\mathrm{NO}$ on alleviation of oxidative stress was also found after plant exposure to cold (Zhao et al., 2009) and drought (Mata and Lamattina, 2001).

Like many other crop plants of tropical or subtropical origin, cultivated tomato (Solanum lycopersicon Mill.) is sensitive to chilling as well as freezing temperatures. Temperatures below $10^{\circ} \mathrm{C}$ inhibit growth, and those under $6^{\circ} \mathrm{C}$ may cause irreparable damage (Geisenberg and Stewart, 1986). Since the particular climatic conditions of the Mediterranean permit off-season production, tomato is often sown in winter or in early spring in cold greenhouses, plastic tunnels and seedbeds, or directly in the field. In early 
sowing, periods with suboptimal temperatures close to the minimum germination temperatures are frequently encountered. In these conditions, seedling emergence may be reduced, delayed and spread over time (Leskovar and Sims, 1987).

Treatments to enhance seed vigour have been proven to be very effective in achieving rapid and uniform seed germination. The priming treatment may constitute a useful tool in overcoming the problems described above and, thus, assuring a high probability of successful establishment for each seed planted. Since some tomato genotypes are more sensitive to cold than others, it is possible that priming could make these genotypes germinate as fast as the cold-tolerant ones. Furthermore, it could also improve the performance of the cold-tolerant ones (Dahal et al., 1990).

Chen and Arora (2012) proposed a model illustrating the cellular physiology of priming-induced stress tolerance, which is likely achieved via two strategies. First, seed priming sets in motion germination-related activities, such as respiration (Corbineau et al., 2000), endosperm weakening (Dahal et al., 1990), embryo enlargement and transcription and translation (Schwember and Bradford, 2010), that facilitate the transition of quiescent dry seeds to germination and improve germination potential. Second, priming imposes an abiotic stress on seeds that represses radicle protrusion but stimulates stress responses, e.g. the accumulation of late embryogenesis abundant (LEA) proteins (Capron et al., 2000), potentially inducing cross-tolerance. Together, these two strategies constitute a 'priming memory' in seeds, which can be recruited upon a subsequent stress exposure to mediate greater stress-tolerance of germinating primed seeds (Chen and Arora, 2012). Seed priming accelerates germination and improves seedling uniformity in many crops (Cayuela et al., 1996; Benamar et al., 2003; Farooq et al., 2006), especially where they are grown under unfavourable environmental conditions (Dahal et al., 1990; Tiryaki et al., 2009; Amooaghaie, 2011).

Currently, the major focus of priming research is on optimizing protocols to improve germination performance. However, only a few biochemical studies have investigated enzymatic antioxidant activities during and after priming (Bailly, 2004; Amooaghaie et al., 2010; Chen et al., 2010b; Amooaghaie, 2011). Even fewer attempts have been made to understand the cellular and molecular mechanisms and signalling pathways of stress tolerance induced by priming (Chen and Arora, 2012).

The objective of the present study was to investigate the effects of exogenous SNP and osmopriming on germination, seedling vigour and suboptimal temperature tolerance of the two tomato genotypes Falcato and Cherry. Furthermore, a possible signalling role of $\mathrm{NO}$ in priming-induced responses was investigated.

\section{Materials and methods}

\section{Plant material and treatments}

Seeds of two tomato genotypes (Falcato, Cherry), were used to investigate the effects of priming on seed germination, seedling vigour and low-temperature tolerance. Seed treatments included ospriming in polyethylene glycol solution (PEG 6000; Shanghai Chemical Reagent Co. Ltd, Shanghai, China) at $300 \mathrm{gl}^{-1}, 200 \mu \mathrm{M}$ sodium nitroprusside (SNP) as NO donor (Merck, Darmstadt, Germany), $100 \mu \mathrm{M}$ methylene blue (MB; Fluka, Shanghi, China), $200 \mu \mathrm{M}$ SNP $+100 \mu \mathrm{M}$ MB, PEG $+100 \mu \mathrm{M} \mathrm{MB}$, and distilled water as control (Con). For osmopriming, seeds were primed with continuous aeration. After $24 \mathrm{~h}$ at $25^{\circ} \mathrm{C}$, the seeds were removed, rinsed in distilled water, wiped free of water and air-dried at $25^{\circ} \mathrm{C}$ for $24 \mathrm{~h}$. For SNP or MB treatments, seeds were presoaked for $1 \mathrm{~d}$ in these solutions. As controls, seeds were soaked in distilled water for $1 \mathrm{~d}$ and then transferred to Petri dishes immediately.

Laboratory seed germination tests were conducted in incubators in 9-cm Petri dishes (50 seeds each per plate and three replicates for each treatment) on a layer of filter paper moistened with distilled water. Seeds were incubated in controlled-growth chambers at 10, 15, 20 and $25^{\circ} \mathrm{C}$. Seed germination was counted daily and counts continued until no further germination occurred for three consecutive days. Seeds were considered germinated when radicles had protruded for more than $2 \mathrm{~mm}$. Germination rate (GR) and germination index (GI) were calculated as described by the Association of Official Seed Analysts (AOSA) (1983), using the following formulae:

$$
\begin{aligned}
& \mathrm{GI}=\sum G t / D t \\
& \mathrm{GR}=\sum(n / t)
\end{aligned}
$$

in which $G t$ is the number of germinated seeds in $t$ days; $D t$ is the number of corresponding germination days; $n$ is the cumulative number of germinated seeds in $t$ days.

Root and shoot length were measured $7 \mathrm{~d}$ after the time of radicle protrusion. The vigour index was determined by the following equation:

$$
\begin{aligned}
\text { Vigour index }=\mathrm{VI}= & \text { seedling length } \\
& \times \text { germination percentage. }
\end{aligned}
$$

\section{Biochemical analysis}

All biochemical parameters (amylase activity, sugar content and NO content) were measured $12 \mathrm{~h}$ after incubation before any radicle protrusion took place. 


\section{Measurement of $\alpha$ - and $\beta$ - amylase and soluble sugars}

Alpha- and $\beta$-amylase activities of seeds at different temperatures were determined using the method of Bernfeld (1955), based on the reduction of free maltose, resulting from the enzymatic hydrolysis of starch, by 3,5-dinitrosalicylic acid, resulting in the formation of orange-coloured 3-amino-5-nitrosalicylic acid, which was determined colorimetrically at $540 \mathrm{~nm}$. The activity of both enzymes was expressed as $\mu$ moles maltose $(\mathrm{g} \text { seed })^{-1}$. Soluble sugars were analysed by the anthrone method (Fales, 1951).

\section{NO measurement}

NO production was determined according to the method described by Zhou et al. (2005) with slight modifications. Samples were ground in a mortar and pestle in $3 \mathrm{ml}$ of $50 \mathrm{mM}$ cold acetic acid buffer $(\mathrm{pH}=3.6$, containing $4 \%$ zinc diacetate). The homogenates were centrifuged at $10,000 \mathrm{~g}$ for $15 \mathrm{~min}$ at $4^{\circ} \mathrm{C}$. The supernatant was collected. The pellet was washed with $1 \mathrm{ml}$ of extraction buffer and centrifuged as before. The two supernatants were combined and $0.1 \mathrm{~g}$ of charcoal was added. After vortexing and filtration, the filtrate was collected. A mixture of $1 \mathrm{ml}$ of filtrate and $1 \mathrm{ml}$ of Greiss reagent was incubated at room temperature for $30 \mathrm{~min}$. Another identical filtrate which was pretreated with 2-(4-carboxyphenyl)-4,4,5,5-tetramethylimidazoline1-oxyl-3-oxide potassium salt (cPTIO), a specific NO scavenger, for $15 \mathrm{~min}$, was used as a control. Absorbance was assayed at $540 \mathrm{~nm}$. NO content was calculated by comparison with a standard curve of $\mathrm{NaNO}_{2}$.

\section{Statistical analysis}

Seed germination and seedling development experiments were performed as a factorial experiment with completely randomized design with three replicates. Data significance was assessed by analysis of variance and the differences between treatment means were compared by Duncan's multiple range test.

\section{Results}

\section{Seed germination and seedling vigour}

The significant interaction of genotype $\times$ temperature is determined by the different responses of genotypes at low temperatures. In control treatments, germination percentage (GP) at $25^{\circ} \mathrm{C}$ was similar for the two genotypes $\left(100 \%\right.$ for both) but at $10^{\circ} \mathrm{C}$ the difference was significant $(31.0 \%$ for Falcato and $50.3 \%$ for Cherry). GP was not affected significantly at $20^{\circ} \mathrm{C}$ in Cherry $(91.6 \%)$ as compared with $25^{\circ} \mathrm{C}$, but it was significantly reduced at 15 and $10^{\circ} \mathrm{C}$, to 78 and $50.3 \%$, respectively $(P<0.05)$. In contrast, in Falcato, GP was reduced significantly at 20,15 and $10^{\circ} \mathrm{C}$ to 75,56 and $31 \%$, respectively $(P<0.05)$. A similar trend was observed for GI and GR in both genotypes in response to temperature reduction (Fig. 1). However, both priming and SNP pretreatment were able to partly alleviate low-temperature reduced seed germination, which was consistent with the responses of other germination parameters, such as GI (Fig. 1).

A similar trend was observed for root and shoot length of the seedlings and, consequently, the vigour index (VI) in both genotypes in response to temperature reduction. Osmopriming and SNP were effective in promoting greater root and shoot length of seedlings and VI than the control at $10^{\circ} \mathrm{C}$, especially for Falcato (Fig. 2). Although GP, GI, GR, root and shoot length and VI were higher in Cherry than Falcato in all treatments and at all temperatues, osmopriming and SNP improved these parameters to a larger extent in Falcato than Cherry (Figs 1 and 2). For example, at $10^{\circ} \mathrm{C}$, SNP increased shoot and root length of Falcato seedlings by 0.65 and $1.1 \mathrm{~cm}$, respectively, but in Cherry seedlings by 0.4 and $0.6 \mathrm{~cm}$ respectively (Fig. 2).

Alleviation of tomato seed germination and seedling growth inhibition as conferred by osmopriming or SNP pretreatment, could be reversed by the combination of osmopriming, or SNP, plus $\mathrm{MB}$, a blocker of $\mathrm{NO}$ action (Figs 1 and 2).

\section{Sugar content and amylase activity}

Both $\alpha$ - and $\beta$-amylase activities and sugar contents declined significantly in germinating tomato seeds under low-temperature stress as compared to the control ( $P<0.05$, Fig. 3$)$. In contrast, both osmopriming and SNP pretreatments brought about an obvious increase in $\alpha$ - and $\beta$-amylase activities and these responses were accompanied by an accumulation of soluble sugars, especially at $10^{\circ} \mathrm{C}$ (Fig. 3). Application of $\mathrm{MB}$ to the osmopriming and SNP solutions reversed these responses.

\section{NO production driven by priming and SNP pretreatments}

The results above demonstrated that priming-induced responses were sensitive to the NO scavenger. To further confirm whether above priming-driven responses were related to $\mathrm{NO}$ signalling we determined NO contents of the seeds. Low-temperature treatment $\left(10^{\circ} \mathrm{C}\right)$ enhanced $\mathrm{NO}$ levels moderately (Fig. 4), whereas osmopriming and SNP pretreatment produced a very strong increase in NO content that was significantly higher than that of the sample under low-temperature stress alone. When MB was added to the osmopriming or SNP solutions, the rate of NO generation was dramatically inhibited, reaching the 
(a)
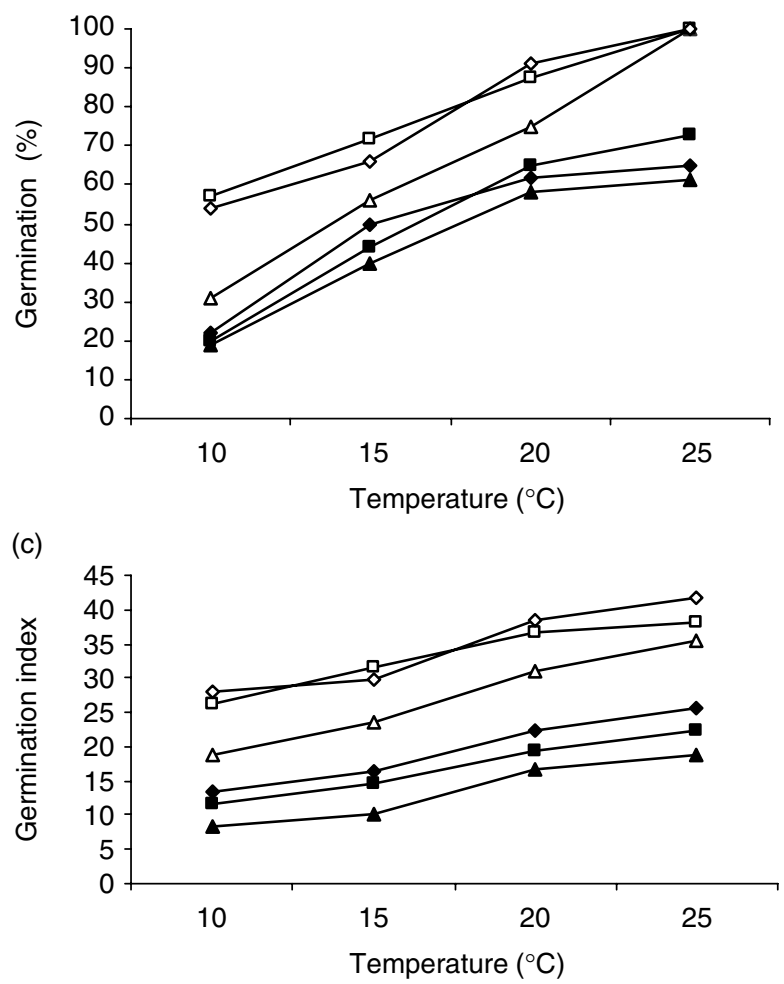

(e)

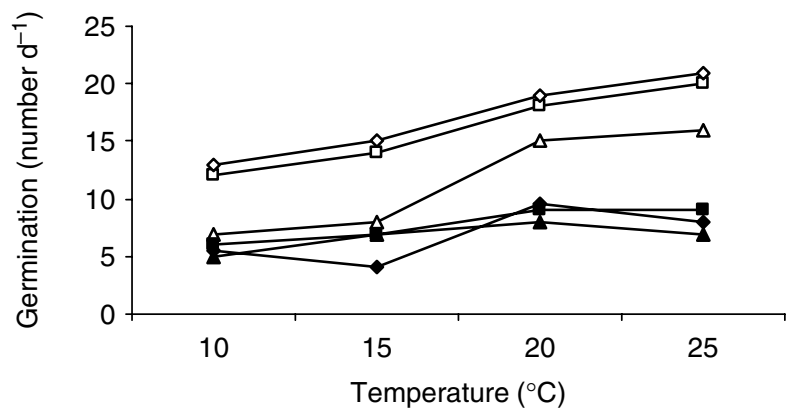

$\neg-$ Control $\multimap-$ Osmopriming $\multimap-$ SNP

$\neg \mathrm{MB} \rightarrow \mathrm{MB}+\mathrm{PEG} \rightarrow \mathrm{MB}+\mathrm{SNP}$ (b)

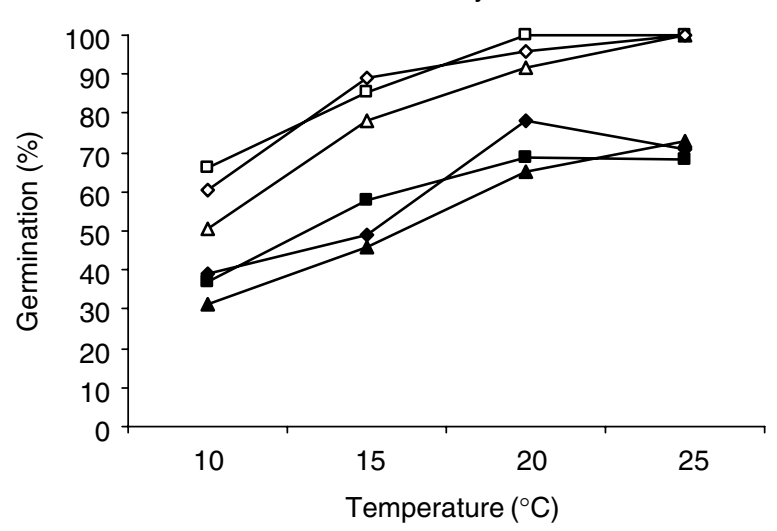

(d)

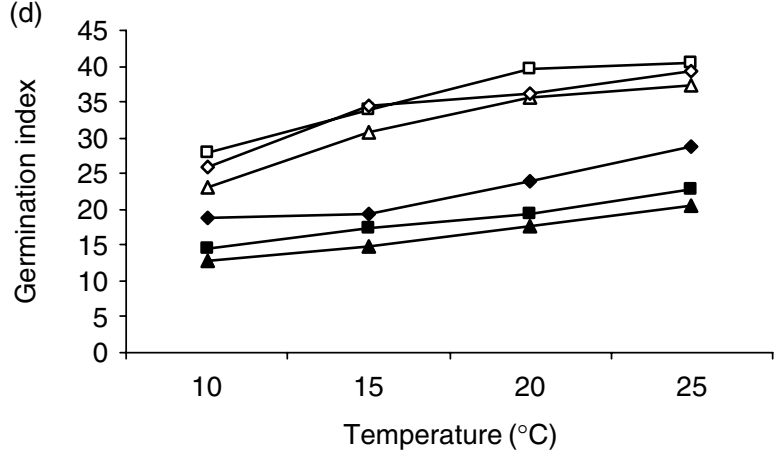

(f)

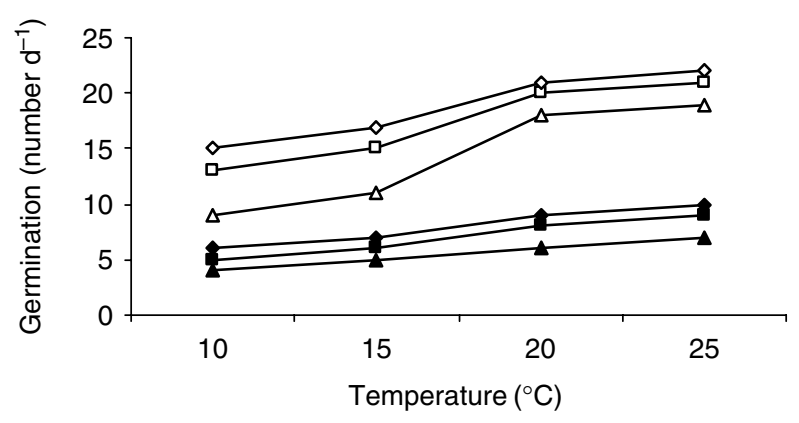

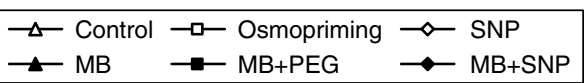

Figure 1. The effects of osmopriming (PEG) and sodium nitroprusside (SNP) and methylene blue (MB) treatments on germination percentage, germination index and germination rate of two tomato genotypes at various temperatures.

basal level of low-temperature stress alone. Interestingly, we also noticed that $\mathrm{MB}$ pretreatment alone significantly resulted in the decrease of $\mathrm{NO}$ production, in comparison with low-temperature stress alone and even compared with the control sample at $25^{\circ} \mathrm{C}(P<0.05)$, suggesting that endogenous NO might be involved in tomato seed germination under both normal and low-temperature stressed conditions. Osmopriming and SNP increased NO content more in Falcato than Cherry (Fig. 4), although higher NO content was observed in Cherry in all treatments.

\section{Discussion}

Most commercial genotypes of tomato (Solanum lycopersicum Mill.), are sensitive to low germination temperatures. Germination temperatures range from a minimum of $8-10^{\circ} \mathrm{C}$ to a maximum of $35-38^{\circ} \mathrm{C}$ with an optimum between 20 and $25^{\circ} \mathrm{C}$ (Geisenberg and Stewart, 1986), which was consistent with our data showing an optimum temperature of $25^{\circ} \mathrm{C}$. With reducing the temperature to $10^{\circ} \mathrm{C}$, the controls showed a concomitant reduction in GP, GI and VI, as well as in 

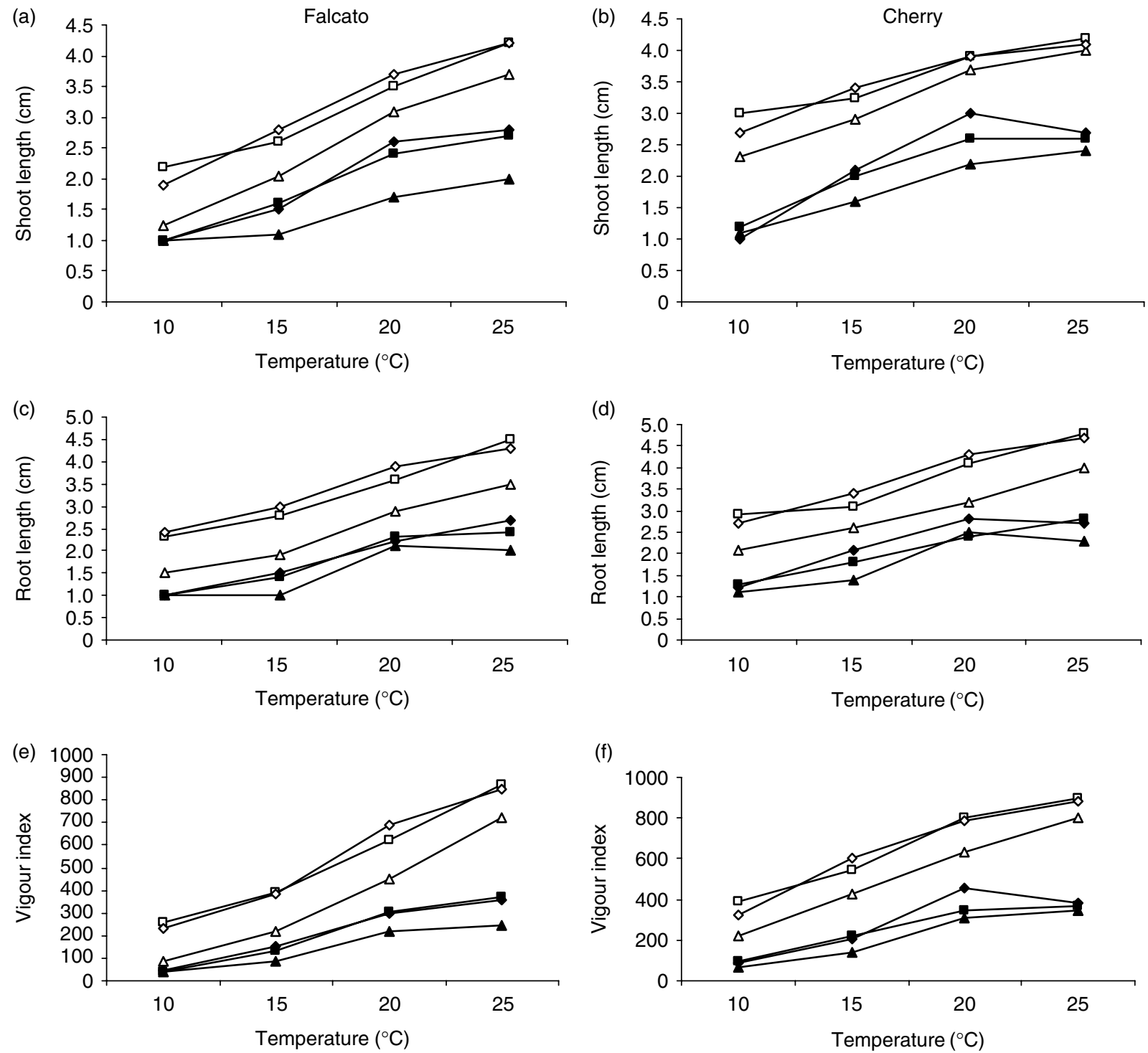

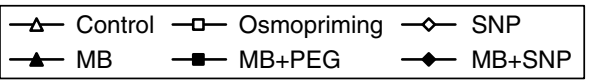

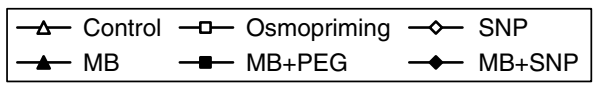

Figure 2. The effects of osmopriming (PEG) and sodium nitroprusside (SNP) and methylene blue (MB) treatments on shoot and root length of seedling and vigour index of two tomato genotypes at various temperatures.

$\alpha$ - and $\beta$-amylase activities, and sugar content in both genotypes. Falcato proved to be more sensitive to low temperature than Cherry. The differences between the two genotypes were likely due to their differing genetic background.

Priming and SNP induced earlier and more uniform germination and stronger seedlings at all temperatures, as indicated by higher GP, GI and VI, but their effect on these parameters was more pronounced at suboptimal temperatures. Both SNP and osmopriming treatments increased amylase activities and levels of soluble sugar in seeds. These sugars would be readily utilized to support the energy and carbon metabolism that are operational during seed imbibition. SNP and osmopriming appeared to stimulate seed germination via a similar biochemical process. Both treatments enhanced amylase activities and seeds contained more soluble sugars, being able to more readily support metabolic activities and consequently resulting in a higher rate of emergence, which correlated with $\alpha$-amylase activity and GI. Enhancement of amylase activity and sugar content by SNP (Zhang et al., 2005; Xu et al., 2011) and priming (Farooq et al., 2006) have been reported by other authors.

Correa-Aragunde et al. (2006) have demonstrated that NO modulates the expression of cell-cycle regulatory genes in tomato and plays a central role in 
(a)

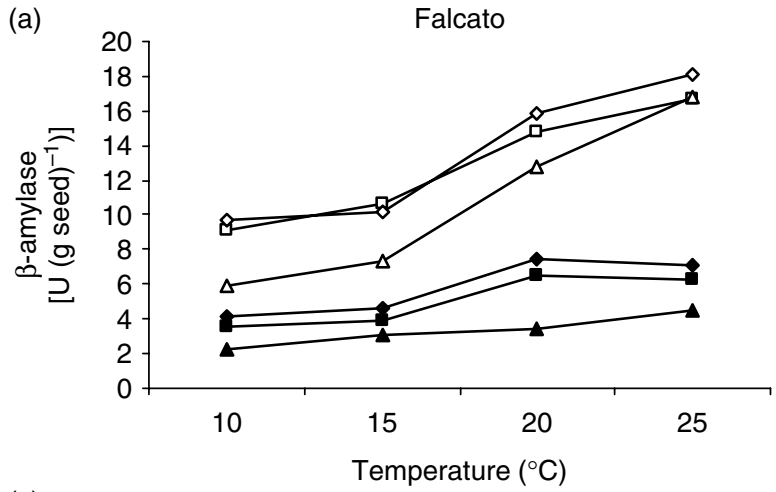

(c)

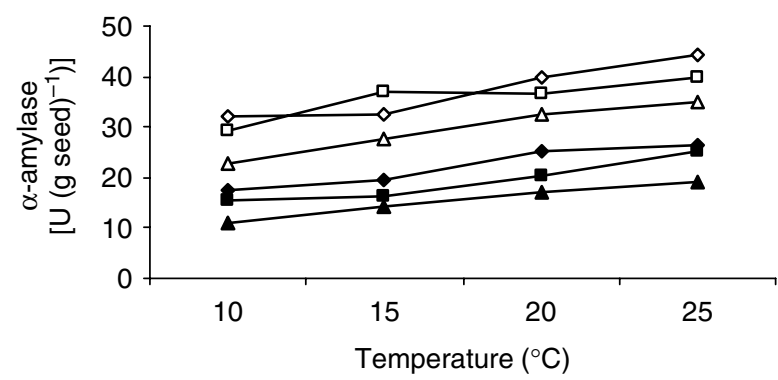

(e)

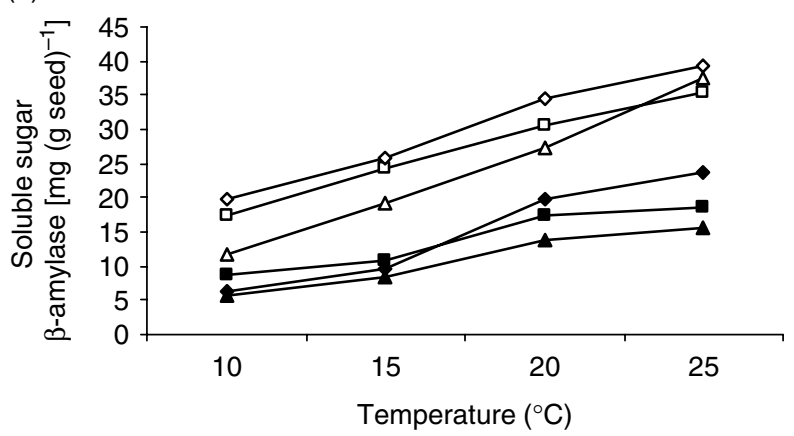

$-\checkmark$ Control $\rightarrow-$ Osmopriming $\multimap$ SNP
$\neg$ MB $\rightarrow-$ MB+PEG $\multimap-$ MB+SNP (b)

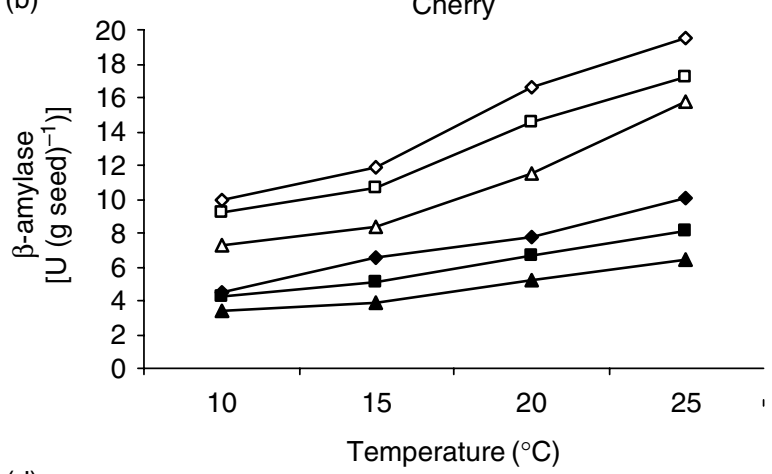

(d)

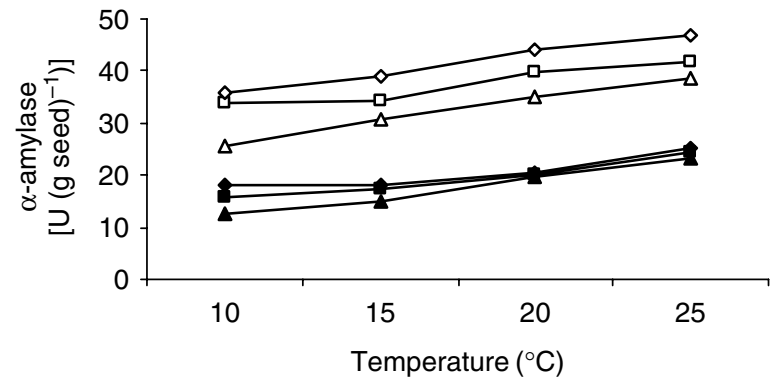

(f)

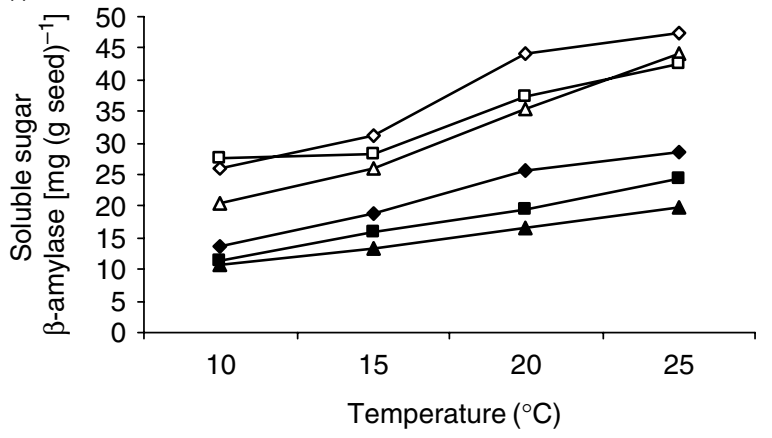

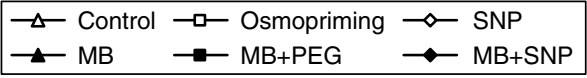

Figure 3. The effects of osmopriming (PEG) and sodium nitroprusside (SNP) and methylene blue (MB) treatments on $\alpha$ - and $\beta$-amylase activities and soluble sugar content in seeds of two tomato genotypes at various temperatures.

determining lateral root development, allowing further understanding of the components that control plant cell differentiation and proliferation. Therefore, the NOinduced increase in seedling growth under suboptimal temperature conditions may have been due to an increase in cell division and/or cell enlargement, although these phenomena were not examined in the present study. Similarly, differential display during maize germination has detected an earlier expression in primed germinating seeds (as compared to unprimed) of ZmAA9-24, a gene encoding a protein believed to regulate cell expansion and elongation (Cruz-Garcia et al., 2003). Our data showed that no difference was observed in seed germination between control and osmopriming and SNP pretreatments at $25^{\circ} \mathrm{C}$, but osmopriming and SNP increased GI, GR and VI.
Probably, seeds can produce just adequate amounts of $\mathrm{NO}$ required for germination at $25^{\circ} \mathrm{C}$ and these treatments probably shortened the time to achieve the required $\mathrm{NO}$ levels for seed germination and subsequent seedling growth. It has been reported that exogenously applied $\mathrm{NO}$ can enhance germination or break seed dormancy (Beligni and Lamattina, 2000), and when no dormancy breakage is required, greater germination rates have been observed by supplementation with an NO donor (Kopyra and Gwóźdź, 2003).

Under low-temperature conditions, SNP and osmopriming resulted in the enhancement of seedling growth of both tomato genotypes, but the enhancement in growth of the low-temperature-sensitive genotype (Falcato) was higher than that of Cherry. Wu et al. (2011) reported that SNP-induced 


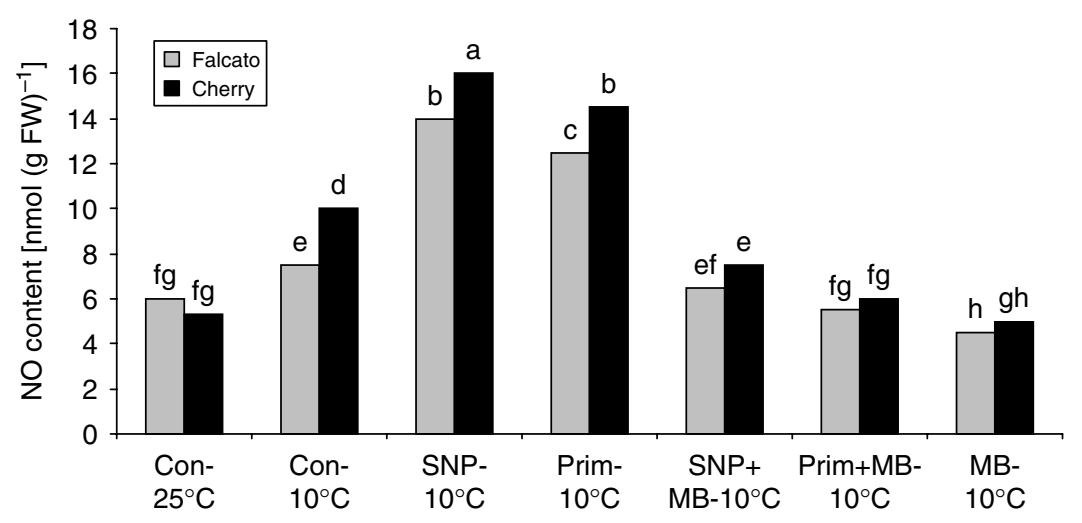

Figure 4. The effects of osmopriming (Prim) and sodium nitroprusside (SNP) and methylene blue (MB) treatments on NO content in two tomato genotypes at various temperatures. Con, control.

enhancement of growth of a salt-sensitive tomato genotype (Hufan2496) was higher than that of a salttolerant genotype (Hufan1480). In addition, external NO could act as a regulator of antioxidant intervention strategy, in preventing oxidative stress in response to cadmium stress in barley seedlings in a genotypedependent pattern (Chen et al., 2010a). On the other hand, suboptimal temperatures increased the $\mathrm{NO}$ content of the controls. Enhancement of endogenous NO content has been reported for plants under cold (Zhao et al., 2009), heat (Song et al., 2006) and salinity (Xu et al., 2011) stresses. NO acts as an important signal in responses against abiotic stress. Therefore, under stress conditions, higher levels of NO are required for the maintenance of cell homeostasis, and once NO is endogenously generated or gets inside the cell from an exogenous source, it enhances stress tolerance (Neill et al., 2003; Delledonne, 2005). Our results suggest that SNP- and osmopriming-induced suboptimal temperature tolerance in seeds is associated with higher $\mathrm{NO}$ contents. Similar roles of SNP have been suggested for lettuce seeds in the darkness (Beligni and Lamattina, 2000), and in salinity-stressed (Zheng et al., 2009) and copper-stressed (Hu et al., 2007) wheat seeds. Furthermore, SNP- and osmopriming-mediated responses appeared to be NO dependent, as they were blocked by treatment with $\mathrm{MB}$, a scavenger of $\mathrm{NO}$. The MB effect on reduction of $\mathrm{NO}$ content and reversal of beneficial effects of SNP on salt tolerance has also been reported for maize (Zhang et al., 2006) and wheat (Xie et al., 2008) seedlings. The beneficial effects of seed priming on germination under stress conditions have been observed in tomato (Dahal et al., 1990; Cavallaro et al., 1994), spinach (Chen et al., 2010b) and white clover (Tiryaki et al., 2009). However, to our knowledge, the present paper is the first report on the effect of osmopriming on NO content of seeds and blocking of the priming responses by $\mathrm{MB}$. Our results highlight the probability of a role of $\mathrm{NO}$ signalling in priming responses.
Two mechanisms may explain the protective action of NO against oxidative damage. First, NO might act on reactive oxygen species (ROS) directly, to form peroxynitrite which is less toxic, thus limiting cellular damage (Martinez et al., 2000) and, second, it might act as a signal in activating ROS-scavenging enzyme activities under abiotic stress (Neill et al., 2003; Delledonne, 2005; Zhou et al., 2005). NO plays an important role in resistance to salt, drought, temperature (high and low), UV-B and heavy metal stress (Lamattina et al., 2003). Song et al. (2006) found that application of SNP and S-nitrose- $\mathrm{N}$-acetylpenicillamine, both NO donors, dramatically alleviated heatstress-induced ion leakage, growth suppression and decrease of cell viability in callus of reed under heat stress, and enhanced the activities of SOD, CAT, APX and POD. Similarly, several authors have reported that priming enhanced accumulation of non-enzymatic compounds and activities of detoxifying enzymes (e.g. SOD, APX, CAT) and improved membrane integrity under stress conditions (Sivritepe, 2008; Amooaghaie et al., 2010; Chen et al., 2010b; Amooaghaie, 2011; Sun et al., 2011). These findings suggest that enzymatic and metabolic activities that are the basis of priming-induced seed invigoration and lowtemperature tolerance, are probably promoted via NO signalling.

Taken together, our results suggest that endogenous NO plays a key role in priming-mediated responses, although we have not explored the potential source of NO driven by priming. Therefore, further investigations should address this question.

\section{Acknowledgements}

This study was supported by research assistance of Shahrekord University, Iran. The authors are grateful to Dr Henk Hilhorst for editing the manuscript and corrections to the English language. 


\section{References}

Amooaghaie, R. (2011) The effect of hydro- and osmoprimng on alfalfa seed germination and antioxidant defense under high salt concentration stress. African Journal of Biotechnology 33, 6269-6275.

Amooaghaie, R., Nikzad, Kh. and Shareghi, B. (2010) The effect of priming on emergence and biochemical changes of tomato seeds under suboptimal temperatures. Seed Science and Technology 38, 508-512.

Association of Official Seed Analysis (AOSA) (1983) Seed vigour testing handbook. Contribution No. 32 to the Handbook on Seed Testing. Springfield, Association of Official Seed Analysis.

Bailly, C. (2004) Active oxygen species and antioxidants in seed biology. Seed Science Research 14, 93-107.

Beligni, M.V. and Lamattina, L. (2000) Nitric oxide stimulates seed germination and de-etiolation, and inhibits hypocotyl elongation, three light-inducible responses in plants. Planta 210, 215-221.

Beligni, M.V., Fath, A., Bethke, P.C., Lamattina, L. and Jones, R.L. (2002) Nitric oxide acts as an antioxidant and delays programmed cell death in barley aleurone layers. Plant Physiology 129, 1642-1650.

Benamar, A., Tallon, C. and Macherel, D. (2003) Membrane integrity and oxidative properties of mitochondria isolated from imbibing pea seeds after priming or accelerated ageing. Seed Science Research 13, 35-45.

Bernfeld, P. (1955) Alpha and beta amylase. pp. 142-158 in Methods in Enzymology Vol. 1. New York, Academic Press.

Bethke, P.C., Libourel, I.G.L., Aoyama, N., Chung, Y., Still, D.W. and Jones, R.L. (2007) The Arabidopsis thaliana aleurone layer responds to nitric oxide, gibberellin, and abscisic acid and is sufficient and necessary for seed dormancy. Plant Physiology 143, 1173-1188.

Capron, I., Corbineau, F., Dacher, F., Job, C., Côme, D. and Job, D. (2000) Sugarbeet seed priming: effects of priming conditions on germination, solubilization of 11-S globulin and accumulation of LEA proteins. Seed Science Research 10, 243-254.

Cavallaro, V., Mauromical, G. and Di Vincenzo, G. (1994) Effects of seed osmoconditioning on emergence characteristics of the tomato (Lycopersicon esculentum Mill.). Acta Horticultura 362, 213-220.

Cayuela, E., Pérez-Alfocea, F., Caro, M. and Bolarín, M.C. (1996) Priming of seeds with $\mathrm{NaCl}$ induces physiological changes in tomato plants grown under salt stress. Physiologia Plantarum 96, 231-236.

Chen, F., Wang, F., Sun, H., Cai, Y., Mao, W., Zhang, G., Vincze, E. and Wu, F. (2010a) Genotype-dependent effect of exogenous nitric oxide on $\mathrm{Cd}$-induced changes in antioxidative metabolism, ultrastructure, and photosynthetic performance in barley seedlings (Hordeum vulgare). Journal of Plant Growth Regulation 29, 394-408.

Chen, K. and Arora, R. (2012) Priming-memory invokes seed stress-tolerance. Environmental and Experimental Botany, doi:10.1016/j.envexpbot.2012.03.005.

Chen, K., Arora, R. and Arora, U. (2010b) Osmopriming of spinach (Spinacia oleracea L. cv. Bloomsdale) seeds and germination performance under temperature and water stress. Seed Science and Technology 38, 45-57.

Corbineau, F., Ozbincol, N., Vinel, D. and Come, D. (2000) Improvement of tomato seed germination by osmopriming as related to energy metabolism. pp. 467-487 in Black, M; Bradford, K.J.; Vazuez-Ramos, J. (Eds) Seed biology: Advances and applications. Wallingford, UK, CABI.

Correa-Aragunde, N., Graziano, M., Chevalier, C. and Lamattina, L. (2006) Nitric oxide modulates the expression of cell cycle regulatory genes during lateral root formation in tomato. Journal of Experimental Botany $57,581-588$.

Cruz-Garcia, F., Gomez, A., Zuniga, J., Plasencia, J. and Vazquez-Ramos, J. (2003) Cloning and characterization of a COBRA-like gene expressed de novo during maize germination. Seed Science Research 13, 209-217.

Dahal, P., Bradford, K.J. and Jones, R.A. (1990) Effects of priming and endosperm integrity on seed germination rates of tomato genotypes. I. Germination at suboptimal temperatures. Journal of Experimental Botany 41, 1431-1439.

del Rio, L.A., Corpas, F.J. and Barroso, J.B. (2004) Nitric oxide and nitric oxide synthase activity in plants. Phytochemistry 65, 783-792.

Delledonne, M. (2005) NO news is good news for plants. Current Opinion in Plant Biology 8, 390-396.

Fales, F.W. (1951) The assimilation and degradation of carbohydrate by yeast cells. Journal of Biological Chemistry 193, 113-124.

Farooq, M., Basra, S.M.A. and Hafeez, K. (2006) Seed invigoration by osmohardening in coarse and fine rice. Seed Science and Technology 34, 181-187.

Geisenberg, C. and Stewart, K. (1986) Field crop management. pp. 511-557 in Atherton, J.G.; Rudich, J. (Eds) The tomato crop: a scientific basis for improvement. London, Chapman and Hall.

Gould, K., Lamotte, O., Klinguer, A., Pugin, A. and Wendehenne, D. (2003) Nitric oxide production in tobacco leaf cells: a generalized stress response? Plant Cell and Environment 26, 1851-1862.

Gouvea, C.M.C.P., Souza, J.F., Magalhaes, A.C.N. and Martins, I.S. (1997) NO releasing substances that induce growth elongation in maize root segments. Plant Growth Regulation 21, 183-187.

Hu, K.D., Hu, L.Y., Li, Y.H., Zhang, F.Q. and Zhang, H. (2007) Protective roles of nitric oxide on germination and antioxidant metabolism in wheat seeds under copper stress. Plant Growth Regulation 53, 173-183.

Kopyra, M. and Gwóźdź, E.A. (2003) Nitric oxide stimulates seed germination and counteracts the inhibitory effect of heavy metals and salinity on root growth of Lupinus luteus. Plant Physiology and Biochemistry 41, 1011-1017.

Lamattina, L., Garcia-Mata, C., Graziano, M. and Pagnussat, G. (2003) Nitric oxide: the versatility of an extensive signal molecule. Annual Review of Plant Biology 54, 109-136.

Leskovar, D.I. and Sims, W.L. (1987) Emergence and yield of tomato (Lycopersicon esculentum Mill.) in response to presowing treatments. Acta Horticultura 20, 145-152.

Martinez, G.R., Mascio, P.D., Bonini, M.G., Agusto, O., Briviba, K. and Sies, H. (2000) Peroxynitrite does not decompose to singlet oxygen and nitroxyl. Proceedings of the National Academy of Sciences, USA 97, 10307-10312.

Mata, G.C. and Lamattina, L. (2001) Nitric oxide induces stomatal closure and enhances the adaptive plant responses against drought stress. Plant Physiology 126, 1196-1204. 
Neill, S., Desikan, R. and Hancock, J.T. (2003) Nitric oxide signaling in plants. New Phytologist 159, 11-35.

Schwember, A.R. and Bradford, K.J. (2010) A genetic locus and gene expression patterns associated with the priming effect on lettuce seed germination at elevated temperatures. Plant Molecular Biology 73, 105-118.

Simontacchi, M., Jasid, S. and Puntarulo, S. (2004) Nitric oxide generation during early germination of sorghum seeds. Plant Science 167, 839-847.

Sivritepe, N. (2008) $\mathrm{NaCl}$ pre-treatments mediate salt adaptation in melon plants through antioxidative system. Seed Science and Technology 36, 360-370.

Song, L., Ding, W., Zhao, M., Sun, B. and Zhang, L. (2006) Nitric oxide protects against oxidative stress under heat stress in the calluses from two ecotypes of reed. Plant Science 171, 449-458.

Sun, H., Lin, L., Wang, X., Wu, S. and Wang, X. (2011) Ascorbate-glutathione cycle of mitochondria in osmoprimed soybean cotyledons in response to imbibitional chilling injury. Journal of Plant Physiology 168, $226-232$.

Tiryaki, I., Kizilsimsex, M. and Kaplan, M. (2009) Rapid and enhanced germination at low temperature of alfalfa and white clover seeds following osmotic priming. Tropical Grass 43, 171-177.

Wu, X., Zhu, W., Zhang, H., Ding, H. and Zhang, H.J. (2011) Exogenous nitric oxide protects against salt-induced oxidative stress in the leaves from two genotypes of tomato (Lycopersicom esculentum Mill.). Acta Physiologia Plantarum 33, 1199-1209.

Xie, Y.J., Ling, T.F., Han, Y., Liu, K.L., Zheng, Q.S., Huang, L.Q., Yuan, X.X., He, Z.Y., Hu, B., Fang, L., Shen, Z.G.,
Yang, Q. and Shen, W.B. (2008) Carbon monoxide enhances salt tolerance by nitric oxide-mediated maintenance of ion homeostasis and up-regulation of antioxidant defense in wheat seedling roots. Plant, Cell $\mathcal{E}$ Environment 31, 1864-1881.

Xu, Sh., Lou, T., Zhao, N., Gao, Y., Dong, L., Jiang, D., Shen, W., Huang, L. and Wang, R. (2011) Presoaking with hemin improves salinity tolerance during wheat seed germination. Acta Physiologia Plantarum 33, 1173-1183.

Zhang, H., Shen, W.B., Zhang, W. and Xu, L.L. (2005) A rapid response of $\beta$-amylase to nitric oxide but not gibberellins in wheat seeds during stage of germination. Planta 22, 545-555.

Zhang, Y., Wang, L., Liu, Y., Zhang, Q., Wei, Q. and Zhang, W. (2006) Nitric oxide enhances salt tolerance in maize seedlings through increasing activities of proton-pump and $\mathrm{Na}^{+} / \mathrm{H}^{+}$antiport in the tonoplast. Planta 224, 545-555.

Zhao, M.G., Chen, L., Zhang, L.L. and Zhang, W.H. (2009) Nitric reductase dependent nitric oxide production is involved in cold acclimation and freezing tolerance in Arabidopsis. Plant Physiology 151, 755-767.

Zheng, C., Jiang, D., Liu, F., Dai, T., Liu, W., Jing, Q. and Cao, W. (2009) Exogenous nitric oxide improves seed germination in wheat against mitochondrial oxidative damage induced by high salinity. Environmental and Experimental Botany 67, 222-227.

Zhou, B., Guo, Z., Xing, J. and Huang, B. (2005) Nitric oxide is involved in abscisic acid-induced antioxidant activities in Stylosanthes guianensis. Journal of Experimental Botany 56, 3223-3228. 